\title{
Knowledge and Awareness among mothers regarding exclusive breastfeeding in holy Karbala city / Iraq
}

maytham salim Al-Nasrawii ( $\sim$ maytham83n@gmail.com )

AL-Furat Al-Awsat Technical University https://orcid.org/0000-0001-8807-9785

Ali Neamah Al-Aaragi

Technical Institute of Karbala

Ali Abd Al-Latif G Mohammed

Technical Institute of Karbala

\section{Research}

Keywords: knowledge, Awareness, Exclusive breastfeeding, Karbala city

Posted Date: December 20th, 2019

DOI: https://doi.org/10.21203/rs.2.19494/v1

License: (c) (i) This work is licensed under a Creative Commons Attribution 4.0 International License.

Read Full License 


\section{Abstract}

Background: World Health Organization (WHO) and United Nations Children's Fund (UNICEF) "Exclusive breastfeeding (EBF)" is explained as "the infant receives only breast milk, no other liquids or solids. Its recommended for the first 6 months of life, and then complementary feeding should be started. EBF helps to reduce child morbidity and mortality from several diseases such as diarrhea, respiratory and /or ear infections and other infectious diseases, shielding lactation women from breast and ovarian cancer. In addition to offers societal economic and environmental benefits, The objective of this study was to assess the knowledge and awareness of exclusive breast feeding among mothers with a child $<2$ years of age.

Methods : A descriptive cross-sectional study was carried out in Health Directorate of Holy Karbala city. The study consist of (487) mothers how attendant to six Primary Health Care center (PHC). The collected data was done by direct interview with mothers and using a questionnaire form that designed based on the study objectives according to WHO criteria. Data were analyzed by SPSS, descriptive statistics included numbers $(\mathrm{N})$ and percentage (\%), and the inferential statistical test was done by using ChiSquare test , P-value was equal or less than 0.05 considered as statistically significant to find for any association between the results variables.

Result : A total of 487 participants were included in the study, the rate of response was $92.7 \%$. The highest percentage $(66.3 \%)$ of study sample were full in the age group (21-30) years, and more than three quarters were lived in urban area. Nearly half of the study sample $47 \%$ had primary education and $60 \%$ those housewives, and the main source of information being family and friends (84.4\%). As an overall assessment, $61.8 \%$ of the study sample had good knowledge and awareness about exclusive Breastfeeding, with highly significant differences to education level, occupation residence of the mother.

Conclusion: Over half of the subjects had good knowledge and awareness of exclusive Breastfeeding. And, on the other hand, there was a very significant difference between education level, occupation and mother's residence with a level of knowledge.

\section{Background:}

Breast milk has the full nutritional requirements for health advancement that a baby needs. Additionally, it is safe and contains antibodies that help protect infants and boost immunity ${ }^{(1)}$. Consequently, breastfeeding contributes to reduced infant morbidity and mortality due to diarrhea, respiratory or ear infections and other infectious diseases ${ }^{(2-4)}$, and for mothers, breast and ovarian cancer risk is reduced ${ }^{(5)}$. In addition, breastfeeding offers societal economic and environmental benefits ${ }^{(6)}$. WHO recommends that children be exclusively breastfed for the first six months of life to achieve optimum growth, development, and health. Children should then obtain complementary foods that are nutritionally adequate and healthy when continuing to the breast for up to two years or more ${ }^{(1)}$. According to WHO and UNICEF "exclusive breastfeeding" is explained as "the infant receives only breast milk, no other 
liquids or solids are given - not even water - with the exception of oral rehydration solution, or drops/syrups of vitamins, minerals or medicines". Its recommended for the first 6 months of life, and then complementary feeding should be started. Whereas, breastfeeding should continue for 2 years age or beyond ${ }^{(7,8)}$.

The aim of this study was to assess the knowledge and awareness towards exclusive breast feeding among mothers had a child aged $<2$ years and find out any association between mothers and knowledge and awareness and some demographic characteristics.

\section{Methods:}

We obtained the ethical and administrative approval on study from the research ethics committee in Karbala Health Directorate. After that, a verbal consent was taken from each mother prior to interview. A cross-sectional study was conducted to achieve the aim of the study. A total of 487 mothers of infants aged (1-24 months) was selected by simple random sampling and direct interviewed during the Period of the study with a response rate of $92.7 \%$. The sample consist of, the mothers who attended six of primary health care (PHC) from Karbala City. Data collected by direct interview with mothers and using a questionnaire form that designed based on the study objectives. The collected data were analyzed by SPSS. The descriptive statistics included numbers $(\mathrm{N})$ and percentage (\%) and the inferential statistical test was done by Chi-Square test, $\mathrm{P}$-value was equal or less than 0.05 considered as statistically significant used to test for any relationship between variables with the results.

\section{Results:}

Table (1) displayed mother age distribution, the highest percentage (66.3\%) was in the age group (21-30) years. Regard to the distribution the type of delivery, this table shows that $(80 \%)$ of the study sample was vaginal delivery; on the other hand, the distribution of residence, education level and the occupation of the respondents, the majority of readings were (76\%), (47\%) and (63\%) in the urban area, primary school and housewife respectively.

Table (1): The distribution of studied sample according to the demographic characteristics. 


\begin{tabular}{|c|c|c|c|}
\hline \multicolumn{2}{|c|}{ The demographic characteristic } & \multicolumn{2}{|c|}{ Total $(\mathrm{N}=487)$} \\
\hline & & No. & $\%$ \\
\hline \multirow[t]{4}{*}{ Age of mother } & $<=20$ & 76 & 15.6 \\
\hline & $21-30$ & 323 & 66.3 \\
\hline & $31-40$ & 82 & 16.8 \\
\hline & $>40$ & 6 & 1.2 \\
\hline \multirow[t]{2}{*}{ Type of delivery } & Vaginal delivery & 386 & 79.3 \\
\hline & caesarean section & 101 & 20.7 \\
\hline \multirow[t]{2}{*}{ Residence } & Urban & 370 & 76 \\
\hline & Rural & 117 & 24 \\
\hline \multirow[t]{4}{*}{ Education level of mother } & Primary school & 229 & 47 \\
\hline & Secondary school & 92 & 18.9 \\
\hline & Institute & 109 & 22.4 \\
\hline & Collage or more & 57 & 11.7 \\
\hline \multirow[t]{2}{*}{ Occupation of Mother } & Housewife & 309 & 63.4 \\
\hline & Other occupation's & 178 & 36.6 \\
\hline
\end{tabular}

As in the field of the knowledge domain, table 2 showed (94\%) of mother answered correctly about definition of (EBF), concerning the time of initiation the breastfeeding (92\%) of study sample had correct answer, while over (80\%) of the participates answered correctly about EBF can be reduce diarrheal, respiratory diseases, decrease hemorrhagic after delivery and helps mothers to get back to their weight before pregnancy quicker. (78.9\%), (67.1) and (41.7\%) of studied sample answered correctly about exclusive breastfeeding prevent pregnancy for at least one year after delivery, colostrum is the first vaccine for newborn and reduce incidence of ( breast and ovarian cancer for mothers), respectively.

Table (2): knowledge Domain of study sample. 


\begin{tabular}{|c|c|c|c|c|c|c|}
\hline \multirow[t]{2}{*}{$\begin{array}{l}\text { Knowledge Domain } \\
\text { about EBF }\end{array}$} & \multicolumn{2}{|l|}{ Yes } & \multicolumn{2}{|l|}{ NO } & \multicolumn{2}{|c|}{$\begin{array}{l}\text { I Don't } \\
\text { know }\end{array}$} \\
\hline & NO. & $\%$ & NO. & $\%$ & NO. & $\%$ \\
\hline EBF is giving breast milk for a minimum of 6 months. & 458 & 94 & 14 & 2.9 & 15 & 3.1 \\
\hline $\begin{array}{l}\text { Must be initiation of breastfeeding immediately at first } \\
\text { hour after delivery. }\end{array}$ & 448 & 92 & 18 & 3.7 & 21 & 4.3 \\
\hline EBF reduce diarrheal and respiratory diseases. & 419 & 86 & 15 & 3.1 & 53 & 10.9 \\
\hline EBF decrease hemorrhagic after delivery. & 409 & 84 & 27 & 5.5 & 51 & 10.5 \\
\hline $\begin{array}{l}\text { BF Helps mothers return more rapidly to their pre- } \\
\text { pregnancy weight. }\end{array}$ & 404 & 83 & 23 & 4.7 & 60 & 12.3 \\
\hline $\begin{array}{l}\text { EBF prevent pregnancy for at least one year after } \\
\text { delivery. }\end{array}$ & 384 & 78.9 & 13 & 2.7 & 90 & 18.5 \\
\hline $\begin{array}{l}\text { Colostrum (breast milk for first } 3 \text { days) is considers the } \\
\text { first vaccine for newborn. }\end{array}$ & 327 & 67.1 & 36 & 7.4 & 124 & 25.5 \\
\hline $\begin{array}{l}\text { EBF reduce incidence of breast and ovarian cancer for } \\
\text { mothers. }\end{array}$ & 203 & 41.7 & 177 & 36.3 & 107 & 22 \\
\hline
\end{tabular}

According to the relationship of knowledge among lactating mothers and the demographic characteristic, not significant with the age of mother (P.value $>0.05$ ), while the association was found to be statistically significant for each of (Type of delivery, Residence, Education level of mother and Mothers occupation) (P.value $<0.05)$ as shown in table (3).

Table (3): The distribution of studied samples according to association of the demographic characteristics with knowledge score. 


\begin{tabular}{|c|c|c|c|c|c|c|}
\hline \multirow[t]{3}{*}{ Categories } & & \multicolumn{4}{|c|}{ Knowledge of mother } & \multirow[t]{3}{*}{ P-value } \\
\hline & & \multicolumn{2}{|c|}{ Poor } & \multicolumn{2}{|c|}{ Good \& Accepted } & \\
\hline & & No. & $\%$ & No. & $\%$ & \\
\hline \multirow[t]{4}{*}{ Age groups } & $<=20$ & 34 & 18.3 & 42 & 14 & \multirow[t]{4}{*}{0.209} \\
\hline & $21-30$ & 125 & 67.2 & 198 & 65.8 & \\
\hline & $31-40$ & 24 & 12.9 & 58 & 19.3 & \\
\hline & $>40$ & 3 & 1.6 & 3 & 1.0 & \\
\hline \multirow[t]{2}{*}{ Type of delivery } & Vaginal delivery & 137 & 73.7 & 249 & 82.7 & \multirow[t]{2}{*}{0.016} \\
\hline & caesarean section & 49 & 26.3 & 52 & 17.3 & \\
\hline \multirow[t]{4}{*}{ Education level } & Primary school & 48 & 25.8 & 181 & 60.1 & \multirow[t]{4}{*}{0.001} \\
\hline & Secondary school & 39 & 21 & 53 & 17.6 & \\
\hline & Institute & 61 & 32.8 & 48 & 15.9 & \\
\hline & Collage or more & 38 & 20.4 & 19 & 6.3 & \\
\hline \multirow[t]{2}{*}{ Occupation } & Housewife & 97 & 52.2 & 212 & 70.4 & \multirow[t]{2}{*}{0.001} \\
\hline & Other occupation's & 89 & 47.8 & 89 & 29.6 & \\
\hline Total & & 186 & 100 & 301 & 100 & \\
\hline
\end{tabular}

\section{Discussion:}

It is very important for all members of the community to understand the importance of EBF for every mother and her baby, for that we assess the knowledge and awareness towards exclusive breast feeding among mothers had a child aged $<2$ years in Karbala city.

In table (1) that illustrate the distribution the mother demographic characteristics, $66.3 \%$ were in the age group (21-30) years, it's the same percentage in age group by Adrawa, A. P et al in Adjumani district $89.9 \%$ and Alamirew, M.W. et al in Ethiopia $66.9 \%{ }^{(8,9)}$.

Regarding the distribution the type of delivery, more than three quarters of the sample $79.3 \%$ had vaginal delivery " Normal delivery " that similar to AL-Abedi, N. et al in AL-Najaf City $74 \%{ }^{(10)}$, on the other hands regarding residency, education level and occupation of the participates, most of the results $76 \%, 47 \%$, and $63 \%$ were from urban area, had primary school and housewife, respectively, that also agreed with ALAbedi, N. et al (2016) and Joshi, S. in Navi Mumbai, Where they recorded their results as $28.7 \%, 30 \%$ and $94 \%, 70 \%$ for primary school and housewife ${ }^{(10,11)}$. 
Concerning to knowledge of mother about exclusive breastfeeding, table 2 showed that differences of answered as correctly about the questions, $94 \%$ of mothers answered correctly about the definition breast milk and $92 \%$ having good awareness towards initiation of exclusive breastfeeding this was similar to other reported study in Navi Mumbai ${ }^{(11)}$ and Sana'a City (2018) by Dallak, A. et al ${ }^{(12)}$. This table also indicates that more than three-quarters of participants were fully aware of exclusive breastfeeding through, decrease hemorrhagic after delivery, helps mothers return to their pre-pregnancy weight and prevent pregnancy for at least one year after delivery. While there was defect (incorrect answers 58.3\%) of study sample knowledge towards reducing the death rate from the breast and ovarian cancer. As overall assessment, figure (2) reveal $61.8 \%$ of the objects had good knowledge, its agreement with the study done by AL-Abedi, N. et al 71\% (2016) and Mbada, et al., (2013) " they reported that overall assessment was good" (13).

Result in (Table 3) refers to an important relationship between mother's awareness and occupational status that is could be due to, housewives are more committed to breastfeeding than female employees, its disagrees with Maryam, et al.,(2014); Mahmud, (2011); Al-Asadi, (2011), all of them stated that a nonsignificant difference among mother's occupations and the knowledge level (14),(15),(16).

For the educational level, there was a highly significant relationship with EBF, its match with the study done by Al-Hially (17), (2010), who reported that there is a significant relationship between mother's education and awareness for breastfeeding, this might be that the " educated mother has better knowledge about breastfeeding more than an uneducated mother".

Mentions that there was a significant correlation between knowledge and delivery type, this can be because natural births are more likely to produce breast milk than cesareans, this result was similar to ALAbedi, N. et al ${ }^{(10)}$. On the other hand, there was a non-significant relationship with Age groups, its disagree with AL-Azzawi, etal.,(2010), who stated that was a significant indicator between age of the mother and knowledge about EBF ${ }^{(18)}$.

Finally, figure (2) reveals the source of information of the study sample about EBF, the study indicates that the highest percentage $84.4 \%$ of participates in this study were received education about exclusive breastfeeding was from family and friends, "Since the majority of participated mothers had primary education, these low educational levels make them incapable to understand and comprehend the educational information in pamphlets, posters, and advanced media. So, they need to be educated about breastfeeding directly from family, friends or health workers, this means that the family plays an important role in successful breastfeeding", its approved with the result do it by Dallak, etal.,(2016), who reported that " the majority of the study sample educated by family and friends for exclusive breastfeeding" (12).

\section{Conclusions:}

There is an urgent necessity to provide accurate prenatal education that focuses on methods and longterm benefits for breastfeeding because mothers don't have inadequate awareness of exclusive 
breastfeeding from where (initiation, colostrum benefits, and breast and ovarian cancer incidence reduction). The study found a highly significant relationship between mother's knowledge and that residence, education level and occupation.

\section{Recommendation:}

In spite of good mother Knowledge toward of EBF, but health education programs for breastfeeding promotion should be well planned and address the factors which reinforce and enable breastfeeding and health team members should be properly trained in breastfeeding essentials and communication skills with the mothers especially in this critical period (child aged $<2$ years) in Karbala city.

\section{List Of Abbreviations}

\begin{tabular}{|ll|}
\hline Abbreviation & Meaning \\
\hline$\%$ & Percent \\
\hline$\&$ & and \\
\hline EBF & Exclusive Breastfeeding \\
\hline N & Number \\
\hline PHC & Primary Health Care center \\
\hline P-value & Probability of chance \\
\hline SPSS & Statistical Package for the Social Sciences \\
\hline UNICEF & United Nations Children's Fund \\
\hline WHO & World Health Organization \\
\hline X2 & Chi-square \\
\hline
\end{tabular}

\section{Declarations}

Ethics approval and consent to participate: Taken from Technical Institute of Karbala committee.

Consent for publication: Technical Institute of Karbala committee

Availability of data and material: Availability of data from Primary Health Care center and the material from self-Authors'.

Competing interests: no competing interests.

Funding: Self. 
Authors' contributions: Not applicable

Acknowledgements: We would like to express my greatest thanks to Dr. Maher Hameed the Dean of the Technical Institute of Karbala, and also I extend my thanks to Dr. Salim Hussein the head of my department for their encouragement, support, guidance to accomplishment of this manuscript.

\section{Authors' information:}

- Maytham Salim AL-Nasrawii / Lecturer / math@atu.edu.iq or maytham83n@gmail.com.

- Ali Neamah Hasan Al-Aaragi / Assist lecturer / alineamah93@gmail.com or alineamah93@atu.edu.iq.

- Ali abd Al - Latif .G. Mohammed / Assist lecturer / ali6@atu.edu.iq

\section{References}

1. Wolde, T., Diriba, G., Wakjira, A., Misganu, G., Negesse, G., Debela, H., ... \& Nekemte, E. (2014). Knowledge, attitude and practice of exclusive breastfeeding among lactating mothers in Bedelle town, Southwestern Ethiopia: Descriptive cross sectional study. Researcher, 6(11), 91-7.

2. Horta, B. L., Victora, C. G., \& World Health Organization. (2013). Short-term effects of breastfeeding: a systematic review on the benefits of breastfeeding on diarrhoea and pneumonia mortality.

3. Bowatte, G., Tham, R., Allen, K. J., Tan, D. J., Lau, M. X. Z., Dai, X., \& Lodge, C. J. (2015). Breastfeeding and childhood acute otitis media: a systematic review and meta- Acta Paediatrica, 104, 85-95.

4. Peres, K. G., Cascaes, A. M., Nascimento, G. G., \& Victora, C. G. (2015). Effect of breastfeeding on malocclusions: a systematic review and meta- Acta Paediatrica, 104, 54-61.

5. Horta, B. L., Loret de Mola, C., \& Victora, C. G. (2015). Long-term consequences of breastfeeding on cholesterol, obesity, systolic blood pressure and type 2 diabetes: a systematic review and meta- Acta Paediatrica, 104, 30-37.

6. Chowdhury, R., Sinha, B., Sankar, M. J., Taneja, S., Bhandari, N., Rollins, N., ... \& Martines, J. (2015). Breastfeeding and maternal health outcomes: a systematic review and meta- Acta paediatrica, 104, 96-113.

7. Abutiheen, A. A. K., Mohammed, R. M. A., Al-Saadi, A. M., Abdulamer, M. A., \& Abotiheen, M. A. (2019). Patterns of Infant Feeding and Factors Associated with Them among Sample of Mothers in Kerbala City. Karbala Journal of Medicine, 12(1), 4124-4131.

8. Adrawa, A. P., Opi, D., Candia, E., Vukoni, E., Kimera, I., Sule, I., ... \& Ovuga, E. (2016). Assessment of the knowledge and practices of exclusive breastfeeding amongst the breastfeeding mothers in Adjumani District, West Nile. East African medical journal, 93(11), 576.

9. Alamirew, M. W., Bayu, N. H., Birhan Tebeje, N., \& Kassa, S. F. (2017). Knowledge and attitude towards exclusive breast feeding among mothers attending antenatal and immunization clinic at Dabat 
Health Center, Northwest Ethiopia: a cross-sectional institution based study. Nursing research and practice, 2017.

10. AL-Abedi, N. F. H., \& Al-Asadi, K. M. N. Assessment of Mother's Knowledge toward Breastfeeding at AL-Najaf City, 2016.

11. Joshi, S. M., Srivathsan, M., \& Velankar, D. H. (2018). Knowledge and awareness of breastfeeding, weaning practices and newborn care in pregnant women in urban areas. International Journal of Community Medicine And Public Health, 6(1), 217-222.

12. Dallak, A., Al-Rabeei, N., \& Aljahmi, Y. (2016). Breastfeeding Knowledge, Attitude, and Practices among Mothers Attending Health Centers in Sana'a City. ARC Journal of Public Health and Community Medicine, 1(2), 9-17.

13. Mbada, C. E., Olowookere, A. E., Faronbi, J. O., Oyinlola-Aromolaran, F. C., Faremi, F. A., Ogundele, A. O., ... \& Augustine, O. A. (2013). Knowledge, attitude and techniques of breastfeeding among Nigerian mothers from a semi-urban community. BMC research notes, 6(1), 552.

14. Maryam, Z., Moniralsadat, H. T., Zohreh, K., Banafsheh, M. Z., \& Amir, S. (2014). The knowledge and attitudes towards breastfeeding of Iranian mothers during the first year after delivery in 2013. Macedonian Journal of Medical Sciences, 7(4), 635-639.

15. Mahmud, N. A. (2011). Knowledge of Breastfeeding: A descriptive study among mothers in Kirkuk Governorate. nursing national Iraqi specility, 24(2), 84-93.

16. Al-Asadi, K. M. N. (2011). Assessment of Mother's Knowledge about NewbornBreast-Feeding. kufa Journal for Nursing sciences, 1(1), 77-84.

17. Al-Hially, Y. A. (2010). Assessment of mothers' knowledge about breast-feeding and determining predictors. Medical Journal of Tikrit, 2(162), 77-83.

18. AL-Azzawi, S. I., \& Shaker, N. Z. (2010). Assessment of Breastfeeding Knowledge among Mothers in Erbil City. Zanco Journal of Medical Sciences (Zanco J Med Sci), 14(2 Special), 1-6.

\section{Figures}




\section{The knowledge score}

Good \&

Accepted;

\section{$61.8 \%$}

\section{Figure 1}

The knowledge score of EBF.

\section{The soures of knowledge}

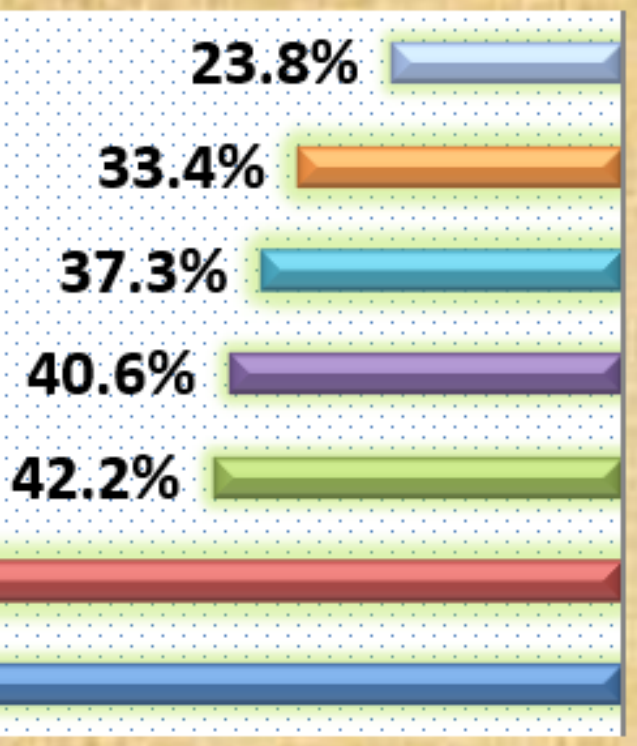

School curriculum local satellite channels workshops

Poster and booklets Internet Health institution Family and Friends

Figure 2 
Distribution the sources of information of study sample.

Page $12 / 12$ 